\title{
Changes in PD-L1 expression according to tumor infiltrating Iymphocytes of acquired EGFR-TKI resistant EGFR-mutant non- small-cell lung cancer
}

Tae-Jung Kim ${ }^{1}$, Soon Auck Hong ${ }^{2}$, Okran Kim ${ }^{3}$, Seung Joon Kim ${ }^{4}$ Ji-Hyun Yang ${ }^{5}$, Eun Kyo Joung ${ }^{5}$, Jin-Hyoung Kang ${ }^{5}$ and Sook-Hee Hong ${ }^{3,5}$

${ }^{1}$ Department of Hospital Pathology, College of Medicine, The Catholic University of Korea, Seoul, Korea

${ }^{2}$ Department of Pathology, Soonchunhyang University Cheonan Hospital, College of Medicine, Soonchunhyang University, Cheonan, Republic of Korea

${ }^{3}$ Cancer Research Institute, The Catholic University of Korea, Seoul, Korea

${ }^{4}$ Division of Respiratory and Critical Care Medicine, Department of Internal Medicine, College of Medicine, The Catholic University of Korea, Seoul, Korea

${ }^{5}$ Division of Medical Oncology, Department of Internal Medicine, College of Medicine, The Catholic University of Korea, Seoul, Korea

Correspondence to: Sook-Hee Hong, email: ssuki76@catholic.ac.kr

Keywords: epidermal growth factor receptor; programmed death receptor ligand 1; CD8+ tumor infiltrating lymphocyte; nonsmall cell lung cancer

Received: August 14, $2017 \quad$ Accepted: October 31, $2017 \quad$ Published: November 21, 2017

Copyright: Kim et al. This is an open-access article distributed under the terms of the Creative Commons Attribution License 3.0 (CC BY 3.0), which permits unrestricted use, distribution, and reproduction in any medium, provided the original author and source are credited.

\section{ABSTRACT}

Backgrounds: EGFR-mutant non-small cell lung cancer (NSCLC) that developed acquired resistance to EGFR-tyrosine kinase (TKI) are potential candidates for programmed death 1 (PD1) inhibitor.

Results: TPS $\geq 1 \%$ for PD-L1 and low CD8 ${ }^{+}$TIL in post-TKI tumor showed a trend for a lower PFS of EGFR-TKIs (14.2 vs 9.9 months; $P=0.060)$ (cohort A). Only 2 of 22 specimens (9.1\%) with an acquired EGFR exon 20 T790M mutation exhibited in post-TKI TPS $\geq 50 \%$ for PD-L1. The degree in post-TKI tumor of PD-L1 expression was varied in 19 patients $(40.5 \%)$, with $10(21.2 \%)$ showing higher levels in the resistant biopsy (cohort B). Among the post-TKI high TPS groups, median PFS with low post- TKI CD8+ TIL scores treated with EGFR-TKIs (6.6 months) was significantly lower than that for the other patients (14.2 months; $P=0.015)$.

Conclusions: The change of PD-L1 expression was accompanied by dynamic change in $\mathrm{CDB}^{+}$TILs and might reflect diverse mechanism of resistance to EGFR-TKI therapy.

Material and Methods: We identified 69 patients (cohort A) with sufficient postTKI tumor tissues and 47 patients (cohort B) with paired tumor tissues available. TPS for PD-L1 expression of tumor cells and CD8 ${ }^{+}$TILs score in tumor specimens were determined by immunohistochemistry.

\section{INTRODUCTION}

Activating mutants of epidermal growth factor receptor (EGFR) are found in $40 \%$ of non-small cell lung cancer (NSCLC) patients in Asia and 10\% of patients in Western countries [1]. Treatment outcome in EGFRmutant NSCLC has been shown to outperform that in other lung cancers owing to the efficacy of EGFR tyrosine kinase inhibitors (EGFR-TKIs) [2, 3]. However, in most cases, resistance to EGFR-TKIs inevitably develops in 1 year [4]. Resistance to third-generation TKIs, which target the resistance mutation T790M in exon 20 acquired in response to first-generation EGFR-TKIs, also inevitably develops within $8-10$ months $[5,6]$. These observations 
highlight the need to develop new treatment strategies, including immunotherapeutics.

Monoclonal antibodies targeting the programmed death 1 (PD1) receptor and its ligand (PD-L1) have recently demonstrated promising antitumor efficacy in NSCLC $[7,8]$. As a first-line therapy, the PD1 inhibitor pembrolizumab has shown significant improvement in overall survival compared with standard platinum doublet chemotherapy in NSCLC with high PD-L1 expression [9]. However, treatment outcomes following immunotherapy was reported to be less effective in patients with EGFRmutant NSCLC than in those with EGFR wild type NSCLC, based on subgroup analyses of Phase III clinical trials [10]. To date, increased PD-L1 expression has been associated with greater benefit of PD1 inhibitor therapy $[8,11]$. However, low expression of both PD-L1 and CD8positive $\left(\mathrm{CD}^{+}\right)$tumor-infiltrating lymphocytes (TILs) in advanced EGFR-mutant NSCLC was reported to underlie the low overall response rate to PD1 inhibitors $[12,13]$. In addition, tumor mutation burden and smoking exposure are also considered potential biomarkers supporting PD1 inhibitor treatment [14]. Generally, EGFR-mutant NSCLCs that develop in those who never smoked tend to have less of a mutation burden than NSCLCs in smokers. However, patients with EGFR-TKI resistant EGFRmutant NSCLC with high tumor PD-L1 expression, but without the EGFR exon 20 T790M mutation, have shown favorable efficacy in nivolumab therapy [15].

Patients with EGFR-mutant NSCLC that have acquired resistance to EGFR-TKI are potential candidates for PD1 inhibitor treatment. Because diverse EGFR-TKI resistance mechanisms, including crosstalk between the tumor and its microenvironment, have been reported, PD-L1 expression and TIL status before developing acquired resistance to EGFR-TKIs may not accurately reflect the status after developing acquired resistance to EGFR-TKIs. Here, we retrospectively analyzed the tumor proportion score (TPS) for PD-L1 expression and $\mathrm{CD}^{+}$TILs in paired tumor tissues from NSCLC patients harboring activating EGFR mutants before and after developing acquired resistance to EGFR-TKIs. In addition, we explored changes in PD-L1 expression and TILs in relation to clinical outcome following EGFRTKI therapy and acquisition of EGFR exon 20 T790M mutations.

\section{RESULTS}

\section{Patient characteristics}

A total of 69 eligible patients with advanced NSCLC were included in the present study (Table 1). The mean age at diagnosis was 60.2 years (range, $34-78.4$ years). Fifty of the 69 patients $(72.5 \%)$ were female and $15(21.7 \%)$ were smokers. With regard to EGFR mutation status, 49 patients harbored a deletion in exon 19 , and 18 patients had an L858R/L861Q missense mutation in exon 21, two of which were uncommon mutations (G719X in exon 18 and S768I in exon 20). Of the 62 patients who underwent EGFR mutation testing after developing acquired resistance to first or second generation EGFR-TKIs, 22 carried the exon 20 T790M mutation. Fifty seven patients were treated with EGFR-TKIs as a first-line therapy and 12 patients were treated with EGFR-TKIs as a second-line therapy. The median PFS for was 13.4 months for first-line EGFR-TKI therapy and 20.4 months for second-line EGFR-TKI therapy.

\section{PD-L1 expression and CD8 ${ }^{+}$TILs in EGFR- mutant NSCLCs after acquired resistance to EGFR-TKIs}

PD-L1 expression was detected in 21 (30.4\%) and 11 (15.9\%) of 69 post-EGFR-TKI specimens using cutoffs of $1-49 \%$ and $\geq 50 \%$ in tumor proportion score (TPS; see Methods), respectively (Table 2). We also observed high-level (grade $\geq 2$ ) $\mathrm{CD}^{+}$TILs in $12(57.2 \%$ ) and $3(27.3 \%)$ in $1-49 \%$ and $\mathrm{TPS} \geq 50 \%$ group, respectively (Table 2). TPS $\geq 1 \%$ for PD-L1 and low $\mathrm{CD}^{+}$TIL in postEGFR-TKI specimens showed a trend for a lower PFS of EGFR-TKIs (9.9 vs 14.2 months; $P=0.060$ ) (Figure 1). The other clinical characteristics were not significantly different (Table 3). 4 of 22 specimens (18.2\%) with an acquired EGFR exon 20 T790M mutation exhibited in TPS $\geq 1 \%$ for PD-L1 and low $\mathrm{CD}^{+}$TIL.

\section{Dynamic changes in PD-L1 expression and $\mathrm{CD8}^{+}$ TILs after EGFR-TKI therapy}

To determine whether targeted therapies affected PD-L1 expression and infiltration of $\mathrm{CD} 8^{+}$lymphocytes, we analyzed the TPS for PD-L1 expression and CD8 $8^{+}$TILs in paired tumor biopsies obtained from patients before starting EGFR-TKIs and after developing resistance to EGFR-TKIs $(n=47$, cohort B). Comparisons of paired pre- and post-EGFR-TKI biopsies showed that the degree of PD-L1 expression was not changed in both biopsies in 28 patients (59.6\%), but varied upon the development of resistance in 19 patients (40.4\%), with 10 showing higher levels of PD-L1 expression in the resistant biopsy $(P=0.999$; Figure $2 \mathrm{~A}$ and $2 \mathrm{~B})$. Twenty one of 27 patients $(77.8 \%)$ with a TPS for PD-L1 of 0\% before EGFR-TKI were also $0 \%$ after EGFR-TKI therapy. The remaining 6 patients showed an increased TPS for PD-L1 expression after EGFR-TKI (Figure 2B). Of these six patients, five also had a high post-EGFR-TKI CD8 $8^{+}$TIL score. In seven of ten patients with a pre-EGFR-TKI TPS for PD-L1 expression in the $1-49 \%$ range, the TPS for PD-L1 changed post-EGFR-TKI as followed; one of three patients with increased TPS for PD-L1 exhibited an high CD8 ${ }^{+}$TIL score post-EGFR-TKI, whereas all of four with decreased TPS for PD-L1 showed a low post-EGFR-TKI 

therapy

\begin{tabular}{|c|c|}
\hline Characteristics & $N=69$ \\
\hline Age (mean, Years) & $60.2(34-78.4)$ \\
\hline $\begin{array}{l}\text { Sex } \\
\quad \text { Men } \\
\text { Women }\end{array}$ & $\begin{array}{l}19(27.5 \%) \\
50(72.5 \%)\end{array}$ \\
\hline $\begin{array}{l}\text { ECOG Performance status } \\
0 \\
1 \\
2\end{array}$ & $\begin{array}{c}47(68.1 \%) \\
18(26.1 \%) \\
4(5.8 \%)\end{array}$ \\
\hline $\begin{array}{l}\text { Smoking history } \\
\text { Current or ex-smoker } \\
\text { Never smoker }\end{array}$ & $\begin{array}{l}15(21.7 \%) \\
54(78.3 \%)\end{array}$ \\
\hline $\begin{array}{l}\text { Clinical stage at diagnosis } \\
\text { Stage IIIB } \\
\text { Stage IVa } \\
\text { Stage IVb }\end{array}$ & $\begin{array}{c}5(7.2 \%) \\
19(27.5 \%) \\
45(65.2 \%)\end{array}$ \\
\hline Presence of brain metastasis & $24(34.7 \%)$ \\
\hline $\begin{array}{l}\text { Histology } \\
\text { Adenocarcinoma } \\
\text { Adenosquamous cell carcinoma } \\
\text { Squamous cell carcinoma }\end{array}$ & $\begin{array}{l}66(95.7 \%) \\
2(2.9 \%) \\
1(1.4 \%)\end{array}$ \\
\hline $\begin{array}{l}\text { EGFR mutation at diagnosis } \\
\text { Exon } 19 \text { del } \\
\text { Exon } 21 \mathrm{~L} 858 \mathrm{R} / \mathrm{L} 861 \mathrm{Q} \\
\text { Exon } 18 \mathrm{G} 719 \mathrm{X} \\
\text { Exon } 20 \mathrm{~S} 768 \mathrm{I}\end{array}$ & $\begin{array}{c}49(71.1 \%) \\
18(26.1 \%) \\
1(1.4 \%) \\
1(1.4 \%)\end{array}$ \\
\hline $\begin{array}{l}\text { Rebiopsy histology } \\
\text { Adenocarcinoma } \\
\text { Small cell carcinoma/neuroendocrine carcinoma } \\
\text { Adenosquamous/Squamous cell carcinoma } \\
\text { Large cell carcinoma } \\
\text { Sarcomatoid carcinoma }\end{array}$ & $\begin{array}{l}59(85.6 \%) \\
4(5.8 \%) \\
4(5.8 \%) \\
1(1.4 \% \\
1(1.4 \%)\end{array}$ \\
\hline $\begin{array}{l}\text { Acquired EGFR Exon } 20 \text { T790M mutation in rebiop } \\
\text { Exon20 T790M } \\
\text { No exon20 T790M } \\
\text { Unknown }\end{array}$ & $\begin{array}{l}22(31.9 \%) \\
40(58.0 \%) \\
7(10.1 \%)\end{array}$ \\
\hline $\begin{array}{l}\text { Treatment just before rebiopsy } \\
\text { EGFR-TKIs } \\
\text { Cytotoxic chemotherapy }\end{array}$ & $\begin{array}{l}57(82.6 \%) \\
12(17.4 \%)\end{array}$ \\
\hline $\begin{array}{l}\text { Median PFS for EGFR-TKIs } \\
\text { First line }(n=53) \\
\text { Second line }(n=16)\end{array}$ & $\begin{array}{c}\text { Median Months }(95 \% \mathrm{CI}) \\
13.4(11.7-15.0) \\
20.4(8.7-32.5)\end{array}$ \\
\hline
\end{tabular}

$\mathrm{CD} 8^{+}$TIL score (Figure 2B). Of the ten patients with a pre-EGFR-TKI TPS $\geq 50 \%$, the post-EGFR-TKI TPS for five was as high or higher than the pre-EGFR-TKI TPS; four of these five patients had a low post-EGFR-TKI CD8 ${ }^{+}$ TIL score (Figure 2B).
We also observed high-level (grade $\geq 2$ ) $\mathrm{CD}^{+}$ TILs in $29(61.7 \%)$ pre-EGFR-TKI specimens and 22 (46.8\%) post-EGFR-TKI specimens. The CD8+ TIL score was consistent between paired pre- and post-EGFR-TKI biopsies in 15 patients $(31.9 \%)$, but changed upon the 
Table 2: Tumor proportion score (TPS) for PD-L1 and CD8 ${ }^{+}$tumor infiltrating lymphocyte (TIL) score after EGFRTKI therapy $(n=69)$

\begin{tabular}{ccccc}
\hline \multicolumn{2}{c}{ Post-TKI PD-L1 } & \multicolumn{2}{c}{ CD8 $^{+}$TIL score } & \multirow{P}{*}{ value } \\
Tumor proportion score & No. of patients & TIL score & No. of patients & \\
\hline $0 \%$ & 37 & $0 / 1+$ & $21(56.7 \%)$ & 0.286 \\
& $(53.6 \%)$ & $2+/ 3+$ & $16(43.3 \%)$ & $9(42.8 \%)$ \\
$1-49 \%$ & 21 & $0 / 1+$ & $12(57.2 \%)$ \\
& $(30.4 \%)$ & $2+/ 3+$ & $8(72.7 \%)$ \\
\end{tabular}

development of resistance in 32 patients $(68.1 \%)$, with 18 $(38.3 \%)$ showing a higher $\mathrm{CD}^{+}$TIL score in the resistant biopsy.

\section{Clinical characteristics of patients with high TPS for PD-L1 expression in resistant biopsies}

To determine the relationship between post-EGFRTKI TPS for PD-L1 expression and clinical characteristics, we defined a post-EGFR-TKI high TPS group for PD-L1 expression who observed higher TPS for PD-L1 in postEGFR-TKI biopsies than paired pre-EGFR-TKI biopsies or not decreased post-EGFR-TKI TPS for PD-L1 $\geq 1 \%$ compared to pre-EGFR-TKI biopsies ( $n=17$, Figure 2B).

Patients in the high post-EGFR-TKI TPS group for PD-L1 expression tended to have a higher pre-TKI CD8 ${ }^{+}$ TIL score than those in the group with a low TPS for PD-L1 expression after EGFR-TKI therapy. However,
post-TKI CD8 ${ }^{+}$TIL scores in the high post-EGFR-TKI TPS for PD-L1 group decreased after developing acquired resistance to EGFR-TKI therapy $(P=0.062)$ compared with that observed in the group with low post-EGFRTKI TPS, which did not significantly change ( $P=0.290$; Figure 2C).

Only 2 of 14 specimens (14.2\%) with an acquired EGFR exon 20 T790M mutation exhibited a high TPS group for PD-L1 expression in post-EGFR-TKI biopsies (Figure 3).

Based on the finding of decreased post-EGFR-TKI CD8 ${ }^{+}$TILs after developing resistance to EGFR-TKIs in the high post-EGFR-TKI TPS group for PD-L1, we individually analyzed TPS for PD-L1 expression and CD8 ${ }^{+}$TILs. This analysis showed that 8 of 17 patients in the high post-EGFR-TKI TPS group for PD-L1exhibited low post-EGFR-TKI CD8 ${ }^{+}$TIL scores (Figure 4A and 4B). The median PFS for the eight patients in this group

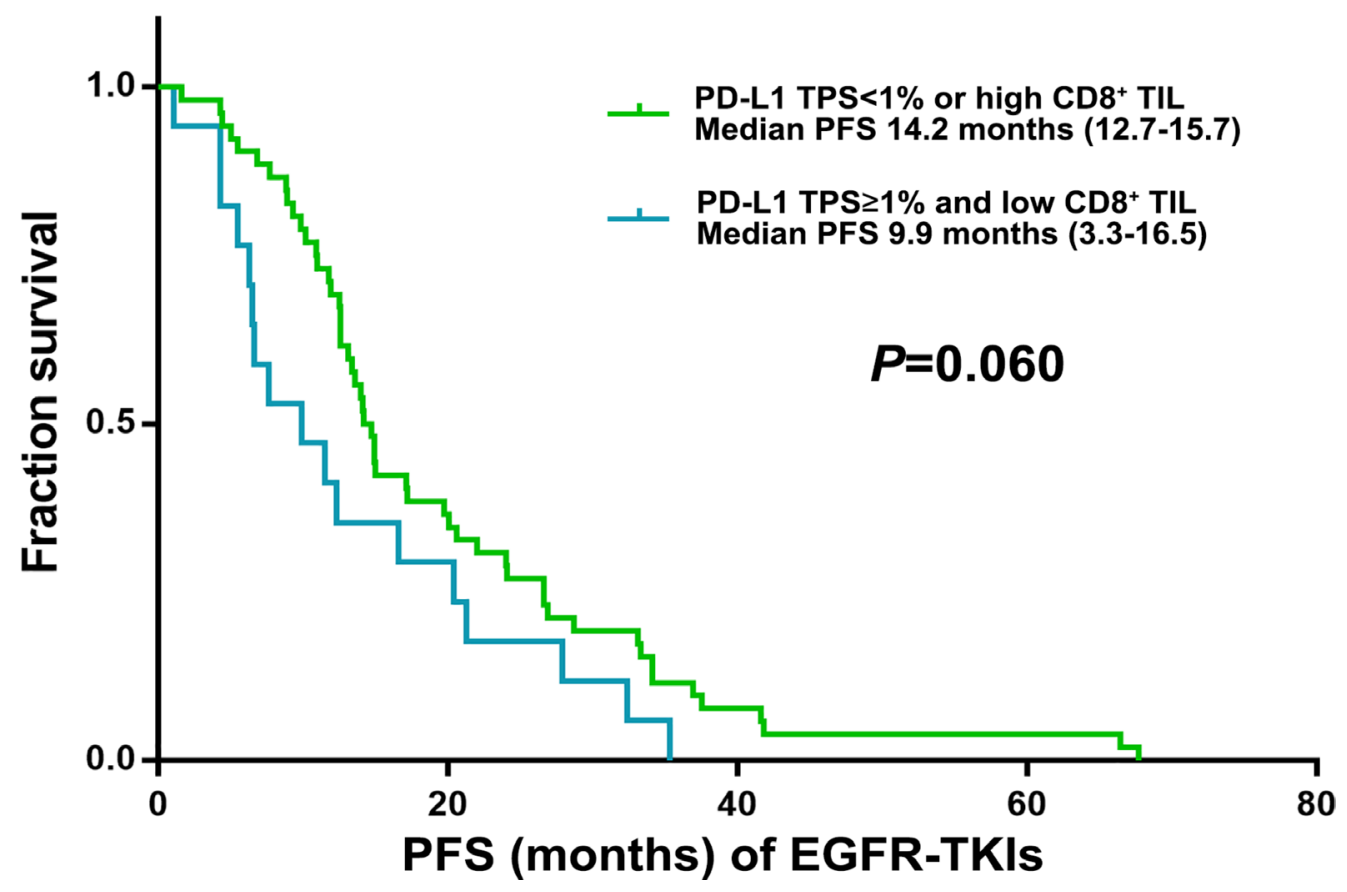

Figure 1: Kaplan-Meier curves for PFS of EGFR-TKI according to post-EGFRT-TKI TPS for PD-L1 and CD8 ${ }^{+}$TILs score $(n=69)$. 
Table 3: Clinical characteristics according to post-EGFR-TKI TPS for PD-L1 and CD8 ${ }^{+}$TIL $(n=69)$

\begin{tabular}{|c|c|c|c|}
\hline TPS for PD-L1/CD8 ${ }^{+}$TIL score & $\begin{array}{c}\text { PD-L1 TPS }<1 \% \\
\text { or high CD8 }{ }^{+} \text {TIL }(n=52)\end{array}$ & $\begin{array}{c}\text { PD-L1TPS } \geq 1 \% \\
\text { and low } \mathrm{CD}^{+} \text {TIL }(n=17)\end{array}$ & $P$ value \\
\hline $\mathrm{M} / \mathrm{F}$ & $14 / 38$ & $5 / 12$ & 1.0 \\
\hline $\begin{array}{l}\text { Smoking } \\
\text { Current or ex-smoker } \\
\text { Never smoker }\end{array}$ & $\begin{array}{l}11(21.2 \%) \\
41(78.8 \%)\end{array}$ & $\begin{array}{l}4(23.5 \%) \\
13(76.5 \%)\end{array}$ & 0.410 \\
\hline $\begin{array}{l}\text { Treatment before rebiopsy } \\
\text { EGFR TKI } \\
\text { Cytotoxic chemo }\end{array}$ & $\begin{array}{l}44(86.4 \%) \\
8(15.4 \%)\end{array}$ & $\begin{array}{c}13(76.5 \%) \\
4(23.5 \%)\end{array}$ & 0.472 \\
\hline Age (mean, Years) & 62.3 & 61.5 & 0.771 \\
\hline $\begin{array}{l}\text { EGFR mutation at diagnosis } \\
\text { Exon } 19 \\
\text { Exon } 21 \text { and others }\end{array}$ & $\begin{array}{l}36(69.2 \%) \\
16(30.8 \%)\end{array}$ & $\begin{array}{c}13(76.5 \%) \\
4(23.5 \%)\end{array}$ & 0.163 \\
\hline PFS (Mo) of EGFR-TKI & $14.2(12.7-15.7)$ & $9.9(3.3-16.5)$ & 0.060 \\
\hline $\begin{array}{l}\text { EGFR Exon } 20 \text { T790M mutation } \\
\text { after EGFR-TKI } \\
\text { Exon20T790M } \\
\text { No exon20 T790M }\end{array}$ & $\begin{array}{l}18(34.6 \%) \\
34(65.4 \%)\end{array}$ & $\begin{array}{l}4(23.5 \%) \\
13(76.5 \%)\end{array}$ & 0.403 \\
\hline $\begin{array}{l}\text { Stage } \\
\text { IIIB/IVA } \\
\text { IVB }\end{array}$ & $\begin{array}{l}16(30.7 \%) \\
36(69.3 \%)\end{array}$ & $\begin{array}{l}8(47.1 \%) \\
9(52.9 \%)\end{array}$ & 0.384 \\
\hline Presence of brain metastasis & $18(34.6 \%)$ & $6(35.3 \%)$ & 0.959 \\
\hline
\end{tabular}

treated with first EGFR-TKIs (6.6 months) was significantly lower than that for the other patients (14.0 months; $P=0.015$ ) (Figure 4C).

\section{DISCUSSION}

In this retrospective study, we evaluated changes in PD-L1 expression and CD8 ${ }^{+}$TILs after developing acquired resistance to EGFR TKI therapy. Gainor et al. recently reported that the expression of PD-L1 was changed in $28 \%$ of patients after EGFR-TKI therapy; Han et al. also reported a marked increase $(38.9 \%)$ in the expression of PD-L1 $[12,16]$. Our study showed that the expression of PD-L1 was changed in $40.9 \%$ of patients, with increasing in $10(22.7 \%)$ of them. Thus, similar to previous studies, our study showed that the expression of PD-L1 changed after EGFR-TKI therapy. Because heterogeneity in PD-L1 expression after EGFR-TKI therapy we analyzed whether changes in PD-L1 expression were related to $\mathrm{CD}^{+}$TIL score. Among 10 patients with increased post-TKI TPS for PD-L1 expression, six showed high in post-TKI $\mathrm{CD}^{+}$TIL score and the other four showed low. Notably, five of ten patients with pre-EGFRTKI TPS for PD-L1 $\geq 50 \%$ showed greater than 50\% post-TKI TPS and four of them showed a low post-EGFRTKI CD ${ }^{+}$TIL score. In contrast, among 6 of 27 patients $(22.2 \%)$ with increased post-EGFR TKI TPS for PD-L1 from pre-EGFR-TKI TPS for PD-L1 $0 \%$, five patients a high post-EGFR-TKI CD8 ${ }^{+}$TIL score. That means high post-EGFR-TKI TPS for PD-L1 group tended to decrease post-TKICD8 ${ }^{+}$TIL score. The PD-L1 expression of this high post-TKI TPS for PD-L1 group may not be related $\mathrm{CD}^{+}$TIL mediated IFN-gamma signaling [17].

In vitro studies of EGFR-mutant lung cancer have shown that the expression of PD-L1 is increased in these cancer cells through downstream effectors in the EGFR pathway, such as STAT3 (signal transducer and activator of transcription 3) and ERK1/2 (extracellular signal-regulated kinase 1/2) [18-20]. These studies also showed that inhibition of the EGFR pathway reduced the expression of PD-L1, suggesting that the oncogenic EGFR pathway is the main mechanism regulating PD-L1 expression in EGFR-mutant lung cancer [18-20]. PD-L1 expression was also increased by the EGFRTKI-resistant oncogenic pathway after acquisition of resistance to EGFR-TKI $[16,20]$. Han et al. reported that PD-L1 expression was increased in tumors exhibiting epithelial mesenchymal transition (EMT) upon developing resistance to EGFR-TKI [16]. Further studies are needed to determine whether an increase in PD-L1 leads directly to EGFR-TKI resistance or is one of the secondary changes in the EGFR-TKI resistance mechanism, such as EMT and amplification of the c-MET or MEK-ERK pathway.

Our data suggest that cases of high post-EGFR-TKI PD-L1 expression and low CD8 ${ }^{+}$TILs could be related 
to innate immune resistance caused by activation of the EGFR-TKI resistant oncogenic pathway [21]. Thus, in the case of higher PD-L1 expression and low CD8 ${ }^{+} \mathrm{TIL}$ post-EGFR-TKI, the duration of tumor control by EGFRTKI therapy decreased. Also, because high $\mathrm{CD}^{+}$TIL is also known to be a predictive indicator for the use of PD1 inhibitors, the low post-EGFR-TKI CD8 ${ }^{+}$TIL suggests that PD1 inhibitors might not be effective even though high PD-L1 expression [13].

Our data suggest that, in patients with both high PDL1 expression and a high CD8 ${ }^{+}$TIL score post EGFR-TKI treatment, the expression of PD-L1 might be related to acquired immune resistance through TILs [17]. Consistent with that infiltration of $\mathrm{CD}^{+}$lymphocytes is an important predictive marker for the efficacy of immunotherapeutic agents, such as those targeting the PD1/PD-L1 pathway, PD1 inhibitor therapy was effective in patients with both increased post-EGFR-TKI PD-L1 expression and CD8 ${ }^{+}$ TIL scores compared with patients exhibiting increased post-EGFR-TKI expression of PD-L1 alone [13]. Haratani et al. recently demonstrated that nivolumab treatment was
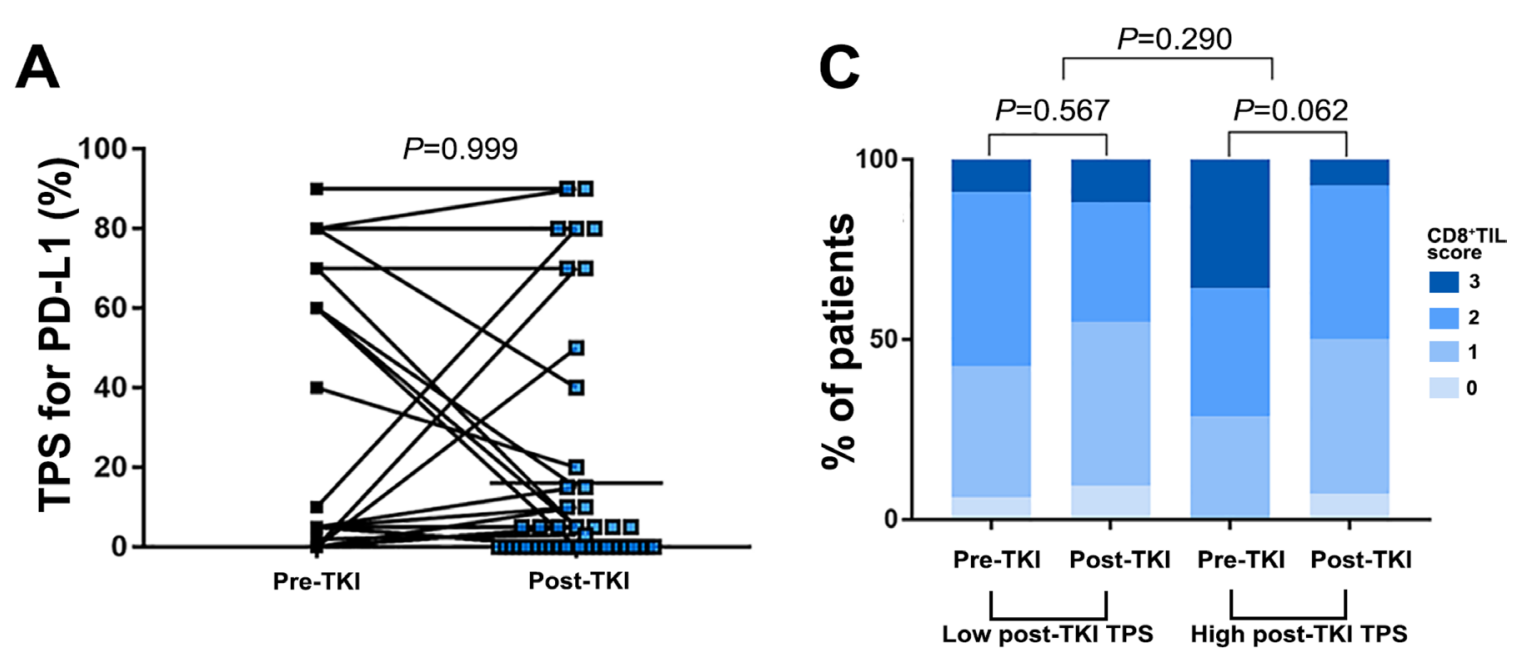

B

$\begin{aligned} & \text { Pre-TKI TPS } \\ & \text { for PD-L1 }\end{aligned}$
No of patients
Post-TKI TPS
For PD-L1
No of patients
Post-TKI
CD ${ }^{+}$TILs HighLow
Low $0+1+1+$
High $2+/ 3+$

highly effective against exon 20 T790M negative EGFRTKI-resistant EGFR-mutant NSCLCs in cases where the EGFR-TKI-resistant tumor expressed high levels of PD-L1 together with high CD8 ${ }^{+}$TIL [15]. They also reported that the proportion of tumors with high expression of PD-L1 was greater among T790M-negative patients than among T790M-positive patients [15]. Our study also showed an increase in post-EGFR-TKI expression of PD-L1 in only 2 of 14 patients harboring the EGFR exon $20 \mathrm{~T} 790 \mathrm{M}$ mutation. It was recently reported that tumor mutation burden in EGFR-TKI-resistant EGFR-mutant NSCLCs might be an important predictive indicator for PD1 inhibitor immunotherapy [15]. EGFR exon 20 T790M mutant EGFR-TKI-resistant tumors were reported to have a lower mutation burden than other EGFR-TKIresistant tumors [15].

Our study has several limitations. First, a small number of patients were included in the study, reflecting difficulties in obtaining appropriate paired biopsies before and after EGFR-TKI therapy. Second, analyses of PD-L1 expression and $\mathrm{CD}^{+}$TILs by immunohistochemical

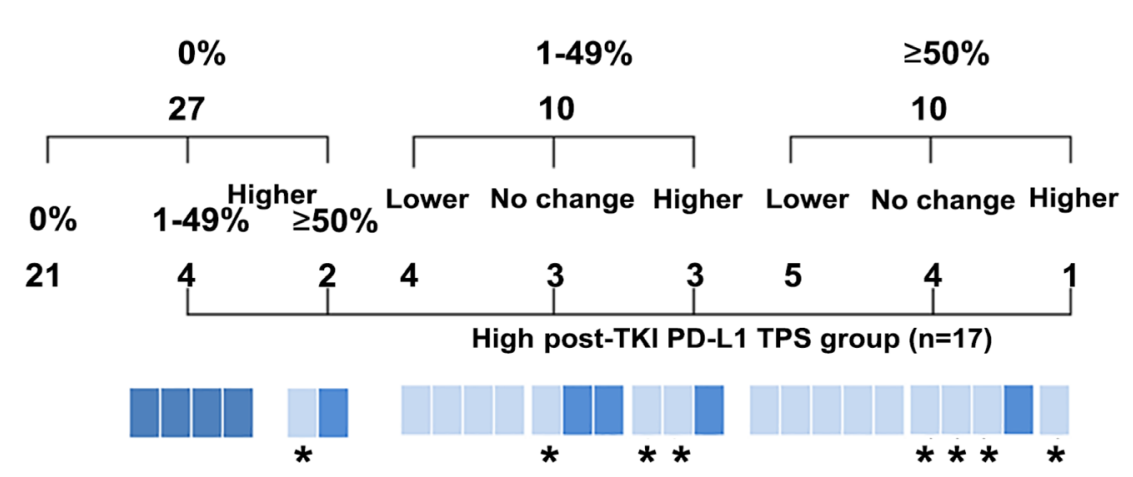

Figure 2: PD-L1 expression and CD8 ${ }^{+}$TILs before and after developing acquired resistance to EGFR-TKI therapy among patients with available paired tissues $(\boldsymbol{n}=\mathbf{4 7})$. (A) Change of TPS for PD-L1in EGFR mutant NSCLC before EGFR-TKI and after developing resistance to EGFR-TKI among the patient with available paired biopsies $(n=47)$. (B) Change of TPS for PD-L1 according to pre-TKI TPS for PD-L1 among the patient with available paired biopsies $(n=47)$. *High post -TKI TPS for PD-L1 and postTKI low CD8 $8^{+}$TILs score patients $(n=8)$. (C) Change of CD8 ${ }^{+}$TILs score in EGFR mutant NSCLC pre-TKI and post-TKI between high and low post-TKI TPS of PDL-1 group among the patient with available paired biopsies $(n=47)$. 
staining have not yet been standardized. For PD-L1 immunostaining, we used a relatively standardized scoring system based on TPS for PD-L1 employing a PharmDx kit; however, different PD-L1 scoring protocols have been used for different PD1 inhibitors. For scoring lymphocyte infiltration, we used a relatively standardized stromal CD ${ }^{+}$ TIL scoring system, and to date there is no standardized $\mathrm{CD}^{+}$TIL scoring protocol for lung cancer [22]. The last practical limitation is related to dynamic changes in PD-L1 expression and CD8 ${ }^{+}$TILs. Because of the relative long-term survival of patients with EGFR-mutant NSCLC, the long-term effects of EGFR-TKI on tumors and the surrounding microenvironment, such as changes in phenotype, heterogeneity of resistance mechanisms, changes in the immune microenvironment and tumorassociated fibrosis, should be analyzed concurrently.

In conclusion, PD-L1 expression changed markedly after developing resistance to EGFR-TKIs. The results of our study suggest that neither post-EGFR-TKI PD-L1 expression nor $\mathrm{CD}^{+}$TIL score are related to pre-EGFRTKI expression of PD-L1 or CD8 ${ }^{+}$TIL. These changes in PD-L1 expression were accompanied by dynamic changes in $\mathrm{CD}^{+}$TILs and might reflect diverse mechanism of resistance to EGFR-TKI therapy. Before considering PD1 inhibitor-based immunotherapy, PD-L1 expression and immune microenvironment status should be reevaluated.

\section{MATERIALS AND METHODS}

We reviewed the medical records of all patients with advanced or recurrent EGFR-mutant NSCLC treated at Seoul St. Mary's Hospital, The Catholic University of Korea, between August 2010 and January 2017, identifying 101 patients who had undergone a rebiopsy or surgery after progression following EGFR-TKI therapy. Cytology specimens were excluded.

For analysis of PD-L1 expression, we identified 69 patients with sufficient archival post-TKI tumor tissue (cohort A) and 47 patients with sufficient paired archival tumor tissue (cohort B) available for analysis (Supplementary Figure 1). Formalin-fixed paraffinembedded tissue was retrieved, and full sections were preferred over biopsies whenever possible. Whole slides were evaluated and he corresponding histology slides were reviewed for tissue adequacy (TJK and SAH). All studies were performed using Institutional Review Board (IRB)approved protocols.

\section{Data collection}

Clinicopathologic features and treatment histories were obtained by reviewing patients' medical records. Data were updated as of June 2017. Responses were assessed according to Response Evaluation Criteria In Solid Tumor (RECIST, v1.1) [23]. Progression free survival (PFS) was measured from the time of treatment initiation to clinical/radiographic progression or death. Patients without documented clinical or radiographic disease progression were censored on the date of last follow-up.

\section{Immunohistochemistry}

Consecutive $3 \mu \mathrm{m}$ thick sections from the formalinfixed, paraffin embedded (FFPE) non-small cell lung cancer (NSCLC) tissue were mounted on Dako FLEX IHC microscope slides, pretreated and stained with the

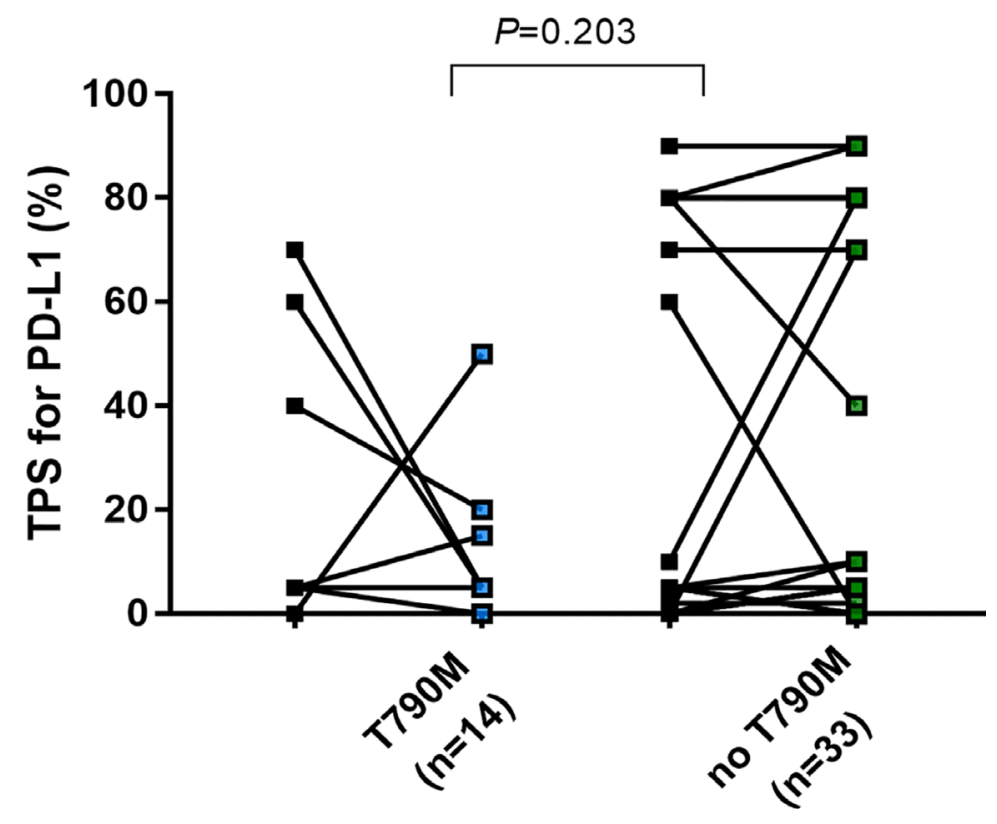

Figure 3: Change of TPS of PD-L1in EGFR mutant NSCLC before EGFR-TKIs and after developing acquired resistance to EGFR-TKIs based on presence of acquired exon20 T790M mutation. 
PD-L1 antibody (clone 22C3) from pharmDx EnVision FLEX visualization system on Autostainer Link 48 (Agilent/Dako, Santa Clara, CA, USA) in accordance with the manufacturers' instructions. PD-L1 staining is well validated and in rountine clinical use [24]. The other consecutive sections were stained with CD8 (1:100, clone C8/144B Agilent/Dako, Santa Clara, CA, USA) Briefly, the samples were heated in Tris-EDTA buffer $(\mathrm{pH} 9.0)$ at $95^{\circ} \mathrm{C}$ for $40 \mathrm{~min}$. To block endogenous peroxidase activity, all the sections were treated with $100 \%$ methanol containing $0.3 \% \mathrm{H}_{2} \mathrm{O}_{2}$ for $15 \mathrm{~min}$. Nonspecific binding of $\mathrm{IgG}$ was blocked by using normal rabbit serum (Agilent/Dako). The sections were incubated with mouse anti-CD8+ monoclonal abs (Agilent/Dako) overnight at $4^{\circ} \mathrm{C}$ Then, they were incubated with biotinylated rabbit-anti-mouse secondary Abs (Agilent/DAKO) followed by the incubation with streptavidin-peroxidase complex solution for $30 \mathrm{~min}$. Signals were generated by incubation with 3,3'-diaminobenzidine. Finally, the sections were counterstained with hematoxylin. Tonsil tissue was included as positive control for both low expression (macrophages in germinal centers) and high expression (crypt epithelium) for all assays. Controls provided with the pharmDx Dako 22C3 assays (sections from cellblocks with PD-L1 positive and negative cell lines) were also included in each run for these assays, in accordance with the manufacturers' instructions. All slides were independently evaluated by two board certified pathologists (TJK, and SAH).

All viable tumor cells on the entire slide was evaluated and included in the PD-L1 scoring assessment. A minimum of 100 viable tumor cells present in the PDL1 stained slide was considered adequate for PD-L1 evaluation. Partial or complete cell membrane staining

\section{A}

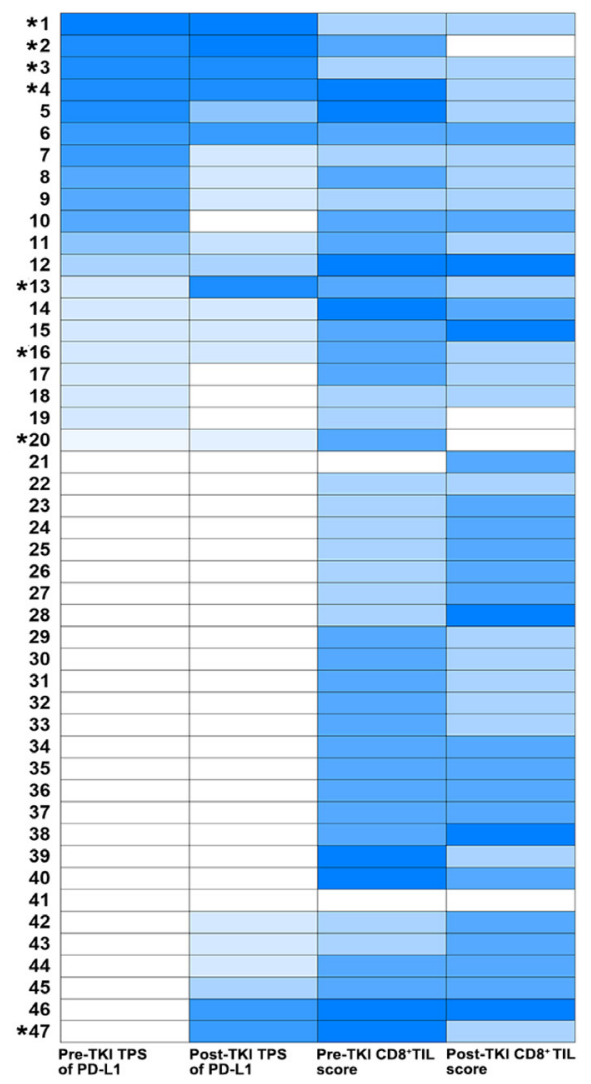

B
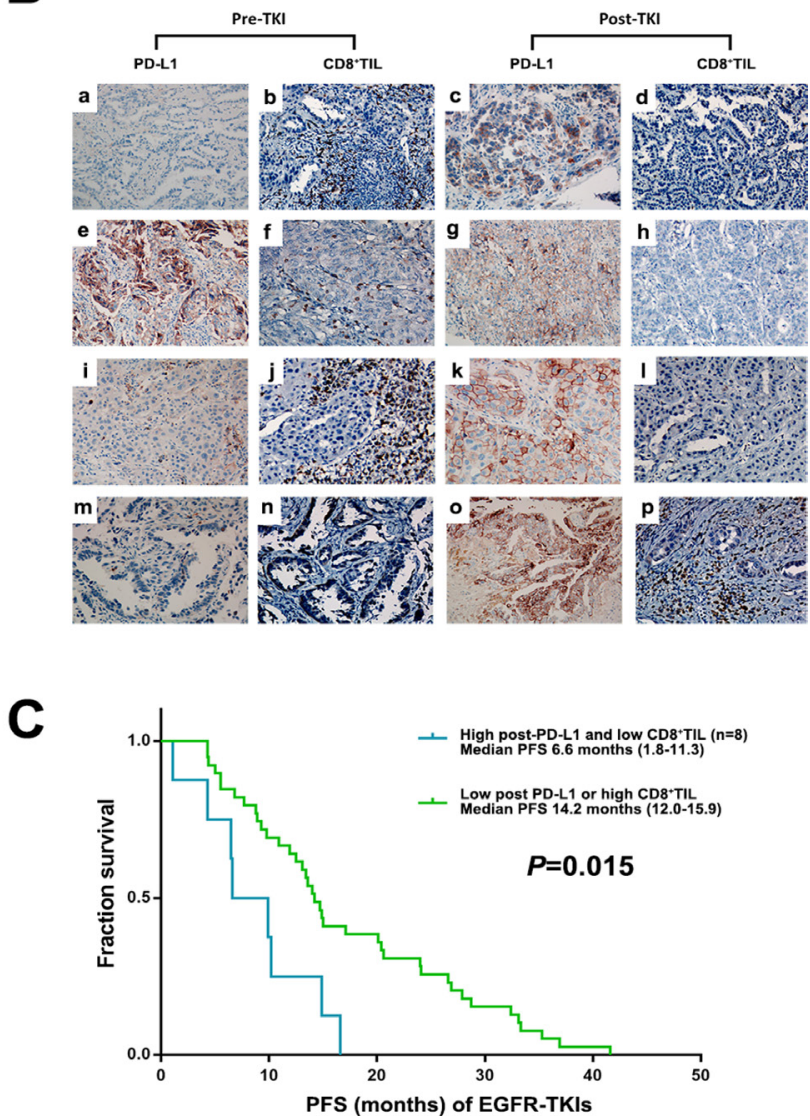

Figure 4: Clinical outcome of EGFR TKIs according to dynamic changes in PD-L1 expression and CD8 ${ }^{+}$TILs score. (A) Change of TPS for PD-L1 and CD8 $8^{+}$TILs in EGFR mutant NSCLC before EGFR-TKIs and after developing acquired resistance to EGFR-TKIs among the patient with available paired biopsies ( ${ }^{*} 8$ patients with high post-TKI TPS for PD-L1 and low CD8 ${ }^{+}$TIL). (B) PD$\mathrm{L} 1$ expression and $\mathrm{CD}^{+}$TILs before and after EGFR- TKIs in paired biopsies with represesntive immunohitochemical images. Pre-TKI with (a) no PD-L1 expression and (b) high CD8 ${ }^{+}$TIL showed post-TKI with (c) high PD-L1 (70\%) and (d) low CD8+ TIL (No. 47 in Figure 4A). Pre-TKI with (e) high PD-L1 expression (80\%) and (f) high CD8 ${ }^{+}$TIL showed post-TKI with (g) high PD-L1 expression (90\%) and (h) low CD8 $8^{+}$TIL (No. 2 in Figure 4A). Pre-TKI with (i) low PD-L1 expression (10\%) and (j) high CD8 ${ }^{+}$TIL showed post-TKI with (k) high PD-L1 (80\%) and (1) low CD8 $8^{+}$TIL (No. 13 in Figure 4A). Pre-TKI with (m) no PD-L1 expression and (n) low CD8 ${ }^{+}$TIL showed post-TKI with (o) high PD-L1 (70\%) and (p) high CD8+ TIL (No. 43 in Figure 4A). (C) Kaplan-Meier curves for PFS of EGFR-TKIs according to post-EGFRT-TKI PD-L1 TPS and CD8 ${ }^{+}$TILs (Log-rank test). 
$(\geq 1+)$ that is perceived distinct from cytoplasmic staining. Cytoplasmic staining was considered non-specific staining and was excluded in the assessment of staining intensity. Normal cells and tumor associated immune cells such as infiltrating lymphocytes or macrophages was separately scored and was not included in the scoring for PD-L1 positivity. PD-L1 protein expression is determined by using Tumor Proportion Score (TPS), which is the percentage of viable tumor cells showing partial or complete membrane staining at any intensity. The specimen should be considered to have no expression (TPS $<1 \%$ ), low PD-L1 expression (TPS $\geq 1 \%$ ) and high PD-L1 expression (TPS $\geq 50 \%$ ) (Supplementary Figure 2) [24]. The degree of $\mathrm{CD} 8^{+}$TILs were semiquantitatively evaluated on a scale of 0 to 3 based on the extent of positive lymphocyte infiltration in the stromal compartment (Supplementary Figure 2) [25]. Each score was defined the percentage of $\mathrm{CD} 8^{+} \mathrm{T}$ cells compared with total nucleated cells in the stromal compartment, as follows: score $0,<5 \%$; score $1,5 \%$ to $25 \%$; score 2 , $25 \%$ to $50 \%$; score $3,>50 \%$ as previously described [25]. Scores were subsequently dichotomized into high (scores 2 and 3 ) and low (scores 0 and 1 ) for increased CD8 $8^{+}$TILs.

\section{Mutational analysis}

Tumor specimens were obtained from each patient using diagnostic or surgical procedures. EGFR mutation testing was performed using nested polymerase chain reaction (PCR) and direct sequencing or a PNA-mediated PCR clamping method (PNAClamp EGFR Mutation Detection Kit; PANAGENE, Inc., Daejeon, Korea) by real-time PCR, as previously described.

\section{Statistical analysis}

Fisher's exact test and the Wilcoxon rank sum test were applied to compare categorical variables and continuous variables, respectively. PFS was estimated by the Kaplan-Meier method using SPSS software (version 24.0; IBM Corp., Armonk, NY, USA). Differences in PFS between cohorts were assessed using a log rank test and were estimated as a hazards ratio (HR) using proportional hazards regression. Paired comparisons of PD-L1 expression and $\mathrm{CD} 8^{+}$TILs between pre- and post-EGFR-TKI specimens from the same patient were evaluated using McNemar's test (a marginal homogeneity test) and Wilcoxon sign-rank test, respectively, depending on whether the immunostaining data were reported as binary, ordinal, or continuous. All $P$-values are based on a two-sided hypothesis; calculations were performed using SPSS version 24.0 (IBM Corp.).

\section{CONFLICTS OF INTEREST}

All authors have no conflicts of interest.

\section{FUNDING}

This research was supported by Basic Science Research Program through the National Research Foundation of Korea (NRF) funded by the 2016 Ministry of Education (2016R1D1A1A02937400).

\section{REFERENCES}

1. Hirsch FR, Bunn PA Jr. EGFR testing in lung cancer is ready for prime time. Lancet Oncol. 2009; 10:432-3. https://doi.org/10.1016/S1470-2045(09)70110-X.

2. Maemondo $\mathrm{M}$, Inoue $\mathrm{A}$, Kobayashi $\mathrm{K}$, Sugawara $\mathrm{S}$, Oizumi S, Isobe H, Gemma A, Harada M, Yoshizawa H, Kinoshita I, Fujita Y, Okinaga S, Hirano H, et al. Gefitinib or chemotherapy for non-small-cell lung cancer with mutated EGFR. N Engl J Med. 2010; 362:2380-8. https:// doi.org/10.1056/NEJMoa0909530.

3. Zhou C, Wu YL, Chen G, Feng J, Liu XQ, Wang C, Zhang S, Wang J, Zhou S, Ren S, Lu S, Zhang L, Hu C, et al. Erlotinib versus chemotherapy as first-line treatment for patients with advanced EGFR mutation-positive nonsmall-cell lung cancer (OPTIMAL, CTONG-0802): a multicentre, open-label, randomised, phase 3 study. Lancet Oncol. 2011; 12:735-42. https://doi.org/10.1016/ S1470-2045(11)70184-X.

4. Yu HA, Arcila ME, Rekhtman N, Sima CS, Zakowski MF, Pao W, Kris MG, Miller VA, Ladanyi M, Riely GJ. Analysis of tumor specimens at the time of acquired resistance to EGFR-TKI therapy in 155 patients with EGFR-mutant lung cancers. Clin Cancer Res. 2013; 19:2240-7. https:// doi.org/10.1158/1078-0432.CCR-12-2246.

5. Janne PA, Yang JC, Kim DW, Planchard D, Ohe Y, Ramalingam SS, Ahn MJ, Kim SW, Su WC, Horn L, Haggstrom D, Felip E, Kim JH, et al. AZD9291 in EGFR inhibitor-resistant non-small-cell lung cancer. N Engl J Med. 2015; 372:1689-99. https://doi.org/10.1056/ NEJMoa1411817.

6. Mok TS, Wu YL, Ahn MJ, Garassino MC, Kim HR, Ramalingam SS, Shepherd FA, He Y, Akamatsu H, Theelen WS, Lee CK, Sebastian M, Templeton A, et al. Osimertinib or Platinum-Pemetrexed in EGFR T790MPositive Lung Cancer. N Engl J Med. 2017; 376:629-40. https://doi.org/10.1056/NEJMoa1612674.

7. Borghaei H, Paz-Ares L, Horn L, Spigel DR, Steins M, Ready NE, Chow LQ, Vokes EE, Felip E, Holgado E, Barlesi F, Kohlhaufl M, Arrieta O, et al. Nivolumab versus Docetaxel in Advanced Nonsquamous Non-Small-Cell Lung Cancer. N Engl J Med. 2015; 373:1627-39. https:// doi.org/10.1056/NEJMoa1507643.

8. Herbst RS, Baas P, Kim DW, Felip E, Perez-Gracia JL, Han JY, Molina J, Kim JH, Arvis CD, Ahn MJ, Majem M, Fidler MJ, de Castro G Jr, et al. Pembrolizumab versus 
docetaxel for previously treated, PD-L1-positive, advanced non-small-cell lung cancer (KEYNOTE-010): a randomised controlled trial. Lancet. 2016; 387:1540-50. https://doi. org/10.1016/S0140-6736(15)01281-7.

9. Reck M, Rodriguez-Abreu D, Robinson AG, Hui R, Csoszi T, Fulop A, Gottfried M, Peled N, Tafreshi A, Cuffe S, O’Brien M, Rao S, Hotta K, et al. Pembrolizumab versus Chemotherapy for PD-L1-Positive Non-Small-Cell Lung Cancer. N Engl J Med. 2016; 375:1823-33. https://doi. org/10.1056/NEJMoa1606774.

10. Lee CK, Man J, Lord S, Links M, Gebski V, Mok T, Yang JC. Checkpoint Inhibitors in Metastatic EGFRMutated Non-Small Cell Lung Cancer-A Meta-Analysis. J Thorac Oncol. 2017; 12:403-7. https://doi.org/10.1016/j. jtho.2016.10.007.

11. Chatterjee M, Turner DC, Felip E, Lena H, Cappuzzo F, Horn L, Garon EB, Hui R, Arkenau HT, Gubens MA, Hellmann MD, Dong D, Li C, et al. Systematic evaluation of pembrolizumab dosing in patients with advanced nonsmall-cell lung cancer. Ann Oncol. 2016; 27:1291-8. https://doi.org/10.1093/annonc/mdw174.

12. Gainor JF, Shaw AT, Sequist LV, Fu X, Azzoli CG, Piotrowska Z, Huynh TG, Zhao L, Fulton L, Schultz KR, Howe E, Farago AF, Sullivan RJ, et al. EGFR Mutations and ALK Rearrangements Are Associated with Low Response Rates to PD-1 Pathway Blockade in Non-Small Cell Lung Cancer: A Retrospective Analysis. Clin Cancer Res. 2016; 22:4585-93. https://doi.org/10.1158/1078-0432. CCR-15-3101.

13. Daud AI, Loo K, Pauli ML, Sanchez-Rodriguez R, Sandoval PM, Taravati K, Tsai K, Nosrati A, Nardo L, Alvarado MD, Algazi AP, Pampaloni MH, Lobach IV, et al. Tumor immune profiling predicts response to anti-PD-1 therapy in human melanoma. J Clin Invest. 2016; 126:3447-52. https://doi.org/10.1172/JCI87324.

14. Rizvi NA, Hellmann MD, Snyder A, Kvistborg P, Makarov V, Havel JJ, Lee W, Yuan J, Wong P, Ho TS, Miller ML, Rekhtman N, Moreira AL, et al. Cancer immunology. Mutational landscape determines sensitivity to PD-1 blockade in non-small cell lung cancer. Science. 2015; 348:124-8. https://doi.org/10.1126/science.aaa1348.

15. Haratani K, Hayashi H, Tanaka T, Kaneda H, Togashi Y, Sakai K, Hayashi K, Tomida S, Chiba Y, Yonesaka K, Nonagase Y, Takahama T, Tanizaki J, et al. Tumor Immune Microenvironment and Nivolumab Efficacy in EGFR Mutation-Positive Non-Small Cell Lung Cancer Based on T790M Status after Disease Progression During EGFR-TKI Treatment. Ann Oncol. 2017; 28:1532-1539. https://doi. org/10.1093/annonc/mdx 183 .

16. Han JJ, Kim DW, Koh J, Keam B, Kim TM, Jeon YK, Lee SH, Chung DH, Heo DS. Change in PD-L1 Expression After Acquiring Resistance to Gefitinib in EGFR-Mutant NonSmall-Cell Lung Cancer. Clin Lung Cancer. 2016; 17: 263-70 e2. https://doi.org/10.1016/j.cllc.2015.11.006.
17. Mandai M, Hamanishi J, Abiko K, Matsumura N, Baba T, Konishi I. Dual Faces of IFNgamma in Cancer Progression: A Role of PD-L1 Induction in the Determination of Pro- and Antitumor Immunity. Clin Cancer Res. 2016; 22:2329-34. https://doi.org/10.1158/1078-0432.CCR-16-0224.

18. Chen N, Fang W, Zhan J, Hong S, Tang Y, Kang S, Zhang Y, He X, Zhou T, Qin T, Huang Y, Yi X, Zhang L. Upregulation of PD-L1 by EGFR Activation Mediates the Immune Escape in EGFR-Driven NSCLC: Implication for Optional Immune Targeted Therapy for NSCLC Patients with EGFR Mutation. J Thorac Oncol. 2015; 10:910-23. https://doi.org/10.1097/JTO.0000000000000500.

19. Zhang N, Zeng Y, Du W, Zhu J, Shen D, Liu Z, Huang JA. The EGFR pathway is involved in the regulation of PD-L1 expression via the IL-6/JAK/STAT3 signaling pathway in EGFR-mutated non-small cell lung cancer. Int J Oncol. 2016; 49:1360-8. https://doi.org/10.3892/ijo.2016.3632.

20. Akbay EA, Koyama S, Carretero J, Altabef A, Tchaicha JH, Christensen CL, Mikse OR, Cherniack AD, Beauchamp EM, Pugh TJ, Wilkerson MD, Fecci PE, Butaney M, et al. Activation of the PD-1 pathway contributes to immune escape in EGFR-driven lung tumors. Cancer Discov. 2013; 3:1355-63. https://doi.org/10.1158/2159-8290.CD-13-0310.

21. Pardoll DM. The blockade of immune checkpoints in cancer immunotherapy. Nat Rev Cancer. 2012; 12:252-64. https:// doi.org/10.1038/nrc3239.

22. Donnem T, Kilvaer TK, Andersen S, Richardsen E, Paulsen EE, Hald SM, Al-Saad S, Brustugun OT, Helland A, Lund-Iversen M, Solberg S, Gronberg BH, Wahl SG, et al. Strategies for clinical implementation of TNMImmunoscore in resected nonsmall-cell lung cancer. Ann Oncol. 2016; 27:225-32. https://doi.org/10.1093/annonc/ $\operatorname{mdv} 560$.

23. Eisenhauer EA, Therasse P, Bogaerts J, Schwartz LH, Sargent D, Ford R, Dancey J, Arbuck S, Gwyther S, Mooney M, Rubinstein L, Shankar L, Dodd L, et al. New response evaluation criteria in solid tumours: revised RECIST guideline (version 1.1). Eur J Cancer. 2009; 45: 228-47. https://doi.org/10.1016/j.ejca.2008.10.026.

24. Roach C, Zhang N, Corigliano E, Jansson M, Toland G, Ponto G, Dolled-Filhart M, Emancipator K, Stanforth D, Kulangara K. Development of a Companion Diagnostic PD-L1 Immunohistochemistry Assay for Pembrolizumab Therapy in Non-Small-cell Lung Cancer. Appl Immunohistochem Mol Morphol. 2016; 24:392-7. https:// doi.org/10.1097/PAI.0000000000000408.

25. Donnem T, Hald SM, Paulsen EE, Richardsen E, Al-Saad S, Kilvaer TK, Brustugun OT, Helland A, Lund-Iversen M, Poehl M, Olsen KE, Ditzel HJ, Hansen O, et al. Stromal CD8+ T-cell Density-A Promising Supplement to TNM Staging in Non-Small Cell Lung Cancer. Clin Cancer Res. 2015; 21:2635-43. https://doi.org/10.1158/1078-0432. CCR-14-1905. 